\title{
Environmental exposure to arsenic may reduce human semen quality: associations derived from a Chinese cross-sectional study
}

Weipan $\mathrm{Xu}^{1 \dagger}$, Huaqiong $\mathrm{Bao}^{2 \dagger}{ }^{\dagger}$, Feng Liu', Liangpo Liu', Yong-Guan Zhu', Jianwen She ${ }^{3}$, Sijun Dong ${ }^{1}$, Min Cai ${ }^{2}$, Lianbing $\mathrm{Li}^{2}$, Chuanhai $\mathrm{Li}^{2}$ and Heqing Shen ${ }^{{ }^{*}}$

\begin{abstract}
Background: Recent observations in in vitro and in vivo models suggest that arsenic (As) is an endocrine disruptor at environmentally-relevant levels. When exposed to As, male rats and mice show steroidogenic dysfunction that can lead to infertility. However, the possible effects of As on human male semen quality remain obscure.

Methods: We monitored the profile of As species in the urine of a reproductive-age human cohort and assessed its association with semen quality. Men $(n=96)$ were recruited in an infertility clinic from July 2009 to August 2010 in the Affiliated Hospital of Chongqing Institute for Population and Family Planning. Five urinary As species were analyzed by high-performance liquid chromatography coupled with inductively coupled plasma mass spectrometry (HPLC-ICP-MS). Clinical information on the semen volume, sperm concentration and motility was employed to catalogue and evaluate semen quality according to WHO guidelines. As species concentrations in addition to other continuous variables were dichotomized by the medians and modelled as categorical variables in order to explore using the binary logistic regression possible associations between As exposure and semen quality.
\end{abstract}

Results: Urinary concentrations (geometric mean $\pm \mathrm{SD}, \mu \mathrm{g} \mathrm{g} \mathrm{g}^{-1}$ creatinine) of different As species were $7.49( \pm 24.8)$ for AsB, 20.9 ( \pm 13.7$)$ for DMA, 2.77 ( \pm 3.33$)$ for MMA, and 4.03 ( \pm 3.67$)$ for Asi (Asill and Asi ${ }^{i}$ ). DMA concentrations above the median were significantly associated with below-reference sperm concentrations $(P=0.02)$ after adjusting for age, body mass index (BMI), abstinence, smoking and drinking habits. In addition, smoking was positively associated with MMA.

Conclusion: Reduced parameters in human semen quality are positively associated with As exposure in a reproductiveage Chinese cohort.

Keywords: Arsenic, China, Cross-sectional study, Human reproduction, Semen quality

\section{Background}

Arsenic (As) is a widely-distributed element in nature, species of which are well-known toxicants. Exposure is associated with a range of adverse effects, including gastroenteritis, neurological manifestations, vascular changes, diabetes and cancers

\footnotetext{
* Correspondence: hqshen@iue.ac.cn

${ }^{\dagger}$ Equal contributors

${ }^{1}$ Key Lab of Urban Environment and Health, Institute of Urban Environment, Chinese Academy of Sciences, 1799 Jimei Road, Xiamen 361021, China

Full list of author information is available at the end of the article
}

(bladder, lung, liver, kidney and prostate) [1]. It is possible to metabolize As into different species via several pathways; one is methylation, which is the major pathway for generation of inorganic As (Asi) in the human body. It has been reported that the metabolic pathway for Asi is a consequence of the following reaction: $\mathrm{Asi}^{\mathrm{V}}+2 \mathrm{e}^{-} \rightarrow \mathrm{Asi}^{\mathrm{III}}+\mathrm{CH}_{3}^{+} \rightarrow \mathrm{MMA}^{\mathrm{V}}$ $\left(\left(\mathrm{CH}_{3}\right) \mathrm{AsO}(\mathrm{OH})_{2}\right)+2 \mathrm{e}^{-} \rightarrow \mathrm{MMA}^{\mathrm{III}}+\mathrm{CH}_{3}^{+} \rightarrow \mathrm{DMA}^{\mathrm{V}}\left(\left(\mathrm{CH}_{3}\right)\right.$ $\left.{ }_{2} \mathrm{AsOOH}\right)+2 \mathrm{e}^{-} \rightarrow \mathrm{DMA}^{\mathrm{III}}+\mathrm{CH}_{3}^{+} \rightarrow$ TMAO (trimethylarsine oxide) [2]. However, this reaction often does not fully metabolize As, and intermediaries, such as Asi, MMA ${ }^{\mathrm{II}}$ and $\mathrm{MMA}^{\mathrm{V}}$, can remain in the body [3,4]. In geographical

\section{Biomed Central}


areas that do not have high levels of As contamination in drinking water, dietary intake is the major exposure route. Thus, consumption of contaminated foods or their processed products are often major contributors to As exposure and subsequent human-health effects.

Toxicity and bioavailability of As depend on its chemical speciation [5]. A number of mechanisms have been proposed to explain As' influence on many disease processes, including possible alteration of cell signalling, cell cycle control, oxidative stress and DNA repair [6-9]. Recently, As has been recognized as an endocrine disruptor because it alters steroid and thyroid hormone receptormediated gene regulation at low and environmentallyrelevant levels in cell culture and whole-animal models. The status of receptors for glucocorticoid, androgen, progesterone, mineralocorticoid, oestrogen, retinoic acid and thyroid hormones is altered [10-14].

As interference with oestrogen receptor (ER)-mediated gene expression [12,15-17] may disrupt the vast network of signalling pathways that are potentially influenced by oestrogens [18]. Although early studies $[19,20]$ reported conflicting results regarding the As effects on fertility in male and female animals, more recent reports suggest that exposure alters female reproductive physiology [16]. Male rats and mice exposed to As exhibited steroidogenic dysfunction that possibly led to infertility [21-24]. It was suggested that chronic As exposure may contribute to male infertility in Comarca Lagunera, Mexico [25] and, has a negative impact on erectile function in a Taiwanese cohort [26]. However, few studies have determined the effects of As on semen quality. Based on the hypothesis that As exposure alters human spermatogenesis, As exposures in a reproductive-age cohort were determined by analyzing in urine various species (arsenobetaine (AsB), DMA ${ }^{\mathrm{V}}, \mathrm{MMA}^{\mathrm{v}}, \mathrm{Asi}^{\mathrm{III}}$ and $\mathrm{Asi}{ }^{\mathrm{V}}$ ) and associating derived profiles with recommended parameters of semen quality.

\section{Materials and methods}

\section{Participant recruitment and urine sample collection}

The study was performed according to the Declaration of Helsinki, and the procedures were approved by the local ethics committee. Study participants were enrolled from July 2009 to August 2010 in the Affiliated Hospital of Chongqing Institute for Population and Family Planning, Chongqing, China. All male partners in infertile couples were asked to participate, without additional exclusion criteria. Every volunteer participant was informed about the purpose of this research, and written informed consent obtained. All participants were married but were childless for unknown reasons. The length of the respective couples' infertility was not recorded. Cross-sectional questionnaires were employed in meeting sessions conducted by trained interviewers who recorded general participant characteristics, including demographics (age, height, weight, religion, etc.), smoking and drinking habits, education status and medical histories. Participants without smoking or drinking histories in the last year were defined as non-smokers or non-drinkers. Male semen quality was assessed and associations with As exposure were explored.

All study participants contributed at least one urine sample. 55\% of the participants contributed two urine samples on separate occasions. For those who contributed two samples, the entire first urine sample was collected on the same day as the semen sample; the mean number of subsequent days to collection of the second sample was $12.77 \%$ of these study participants contributed their second urine sample within 1-7 days from the first contribution. Among the other study participants who contributed two urine samples, $7.3 \%$ of the second urine samples were collected within 12-50 days, and $5.2 \%$ were collected within $66-180$ days postcontribution of the initial samples. The half-life of inorganic arsenic is only 1.5 \pm 0.9$)$ day in the human body [27]. For those contributing two samples, the mean of both derived measurements was used in subsequent analysis. The samples were initially stored at $-40^{\circ} \mathrm{C}$, transported to the analytical laboratory in Xiamen packed in dry ice, and then kept at $-80^{\circ} \mathrm{C}$ until analysis.

\section{Semen collection and analysis}

Study participants were requested to remain abstinent for at least two days before contributing a semen sample. The date of semen collection was recorded. $77 \%$ of semen samples were collected on the same day as that when the participant contributed the corresponding first urine. $15 \%$ were collected 1-6 days prior to urine contribution, $4 \%$ were collected $38-51$ days prior, and $4 \%$ were collected 87-132 days before. Semen samples were collected following masturbation into a sterile plastic specimen cup (NUNC Brand products, USA) and were liquefied at $37^{\circ} \mathrm{C}$ for $30 \mathrm{~min}$ before analysis. Sperm motility, semen volume and sperm concentration were measured according to World Health Organization (WHO) guidelines [28]. Motility parameters were analyzed using a Micro-cell slide and computer-aided semen analysis (CASA, WLJX 9000, Weili New Century Science \& Tech Dev., Beijing, China). According to WHO recommendation, percent motile sperm was scored using categories A (rapid progressive motility), B (slow progressive motility), C (nonprogressive motility), and D (immotility). The category $\mathrm{C}$ group was excluded in this analysis since it is not an independent variable. In addition, previous studies have shown that the percentage of progressively motile spermatozoa $(A+B)$ is the most significant parameter in relation to the male fertility [29]. Therefore, subsequent analysis was 
conducted employing two designated groupings for motility, A + B and D. Sperm morphology was determined using the strict criteria described by Kruger and colleagues [30].

\section{Arsenic (As) determination with HPLC-ICP-MS}

Five As species in urine were simultaneously measured by Agilent 1200 Series liquid chromatography (Agilent Technologies, USA) coupled with Agilent 7500 cx inductively coupled plasma mass spectrometry (Agilent Technologies).

The standards $\left(\mathrm{CH}_{3}\right)_{2} \mathrm{AsOOH}, \quad\left(\mathrm{CH}_{3}\right) \mathrm{AsO}(\mathrm{OH})_{2}$, $\mathrm{Na}_{2} \mathrm{HAsO}_{4} \cdot 7 \mathrm{H}_{2} \mathrm{O}, \mathrm{As}_{2} \mathrm{O}_{3}$ and $\mathrm{AsB}(40 \mathrm{mg} / \mathrm{l})$ were purchased from the National Research Centre for Certified Reference Material in China. Stock solutions were prepared as described. An appropriate amount of $\left(\mathrm{CH}_{3}\right)$ ${ }_{2} \mathrm{AsOOH},\left(\mathrm{CH}_{3}\right) \mathrm{AsO}(\mathrm{OH})_{2}$ and $\mathrm{Na}_{2} \mathrm{HAsO}_{4} \cdot 7 \mathrm{H}_{2} \mathrm{O}$ were each individually dissolved in deionised water $(18.2 \mathrm{M} \Omega)$. $\mathrm{As}_{2} \mathrm{O}_{3}$ was dissolved in $\mathrm{NaOH}(0.1 \mathrm{~N})$ to prepare $1000 \mathrm{mg} \mathrm{L}^{-1}$ of $\mathrm{DMA}^{\mathrm{V}}, \mathrm{MMA}^{\mathrm{V}}, \mathrm{Asi}^{\mathrm{V}}$ and $\mathrm{Asi}{ }^{\mathrm{III}}$. All stock solutions were stored at $4^{\circ} \mathrm{C}$ in polyethylene bottles. A series of standard As solutions, with a range of $0.1-50 \mu \mathrm{g} \mathrm{L} \mathrm{L}^{-1}$, were prepared daily by mixing stock solutions.

A pre-column $(11.2 \mathrm{~mm}, 12-20 \mu \mathrm{m})$ and a Hamilton PRP-X100 anion-exchange column $(250 \mathrm{~mm} \times 4.1 \mathrm{~mm}$, $10 \mu \mathrm{m})$ were used to separate $\mathrm{AsB}, \mathrm{DMA}^{\mathrm{V}}, \mathrm{MMA}^{\mathrm{V}}, \mathrm{Asi}^{\mathrm{II}}$ and $A s i^{V}$ using a flow rate of $1.0 \mathrm{ml} / \mathrm{min}$. The mobile phase was prepared with $10 \mathrm{mM}$ ammonium nitrate and $10 \mathrm{mM}$ diammonium hydrogen phosphate, which had been adjusted to $\mathrm{pH} 9.25$ by ammonium hydroxide. The mobile phase was never stored for $>3$ days at $4^{\circ} \mathrm{C}$ prior to use. The frozen urine samples were defrosted at room temperature for $2 \mathrm{~h}$ prior to analysis. The samples were vortexed, and then, $1 \mathrm{ml}$ of urine was filtered through a $0.22 \mu \mathrm{m}$ polyether sulfone membrane filter and poured into a $1.5 \mathrm{ml}$ autosampler vial [31]. The injection volume was $20 \mu \mathrm{l}$. ICP-MS was operated at a generator power of $1500 \mathrm{~W}$. The cooling gas flow, carrier gas flow and makeup gas flow were $15,1.0$ and $1.1 \mathrm{~L} \mathrm{~min}^{-1}$, respectively. The ICP-MS instrument did not run tests in the collision cell mode because the optimal chromatographic parameters employed in this study separated the ${ }^{40} \mathrm{Ar}^{35} \mathrm{Cl}$ peak from the peaks of the other As species [32]. The $\mathrm{m} / \mathrm{z} 75$ for As and $\mathrm{m} / \mathrm{z} 115$ for the internal standard of indium (In) were monitored with ICP-MS. The peak sequence was listed as AsB, Asi $i^{\mathrm{III}}$, DMA, MMA and $\mathrm{Asi}^{\mathrm{V}}$, and a peak of $\mathrm{ArCl}^{+}(\mathrm{m} / \mathrm{z}=75)$ was eluted between MMA and $A s i{ }^{\mathrm{V}}$.

At the start of sample analysis, calibration curves for As concentrations of $0,0.1,0.5,1,5,10,20$ and $50 \mu \mathrm{g} \mathrm{L}{ }^{-1}$ were analyzed. The standard reference $(0.1$ and $1 \mathrm{ppb})$ was injected into every tenth sample to assess instrumental sensitivity and stability. In addition, the calibration blank was measured to assess any background carryover, and duplicate samples were analyzed to observe reproducibility during analysis. The spiked As species $\left(10 \mu \mathrm{g} \mathrm{L} \mathrm{L}^{-1}\right.$ in 3 urine samples) had a recovery range of $88-105 \%$. The limit of detection (LOD) for the AsB, MMA, DMA and Asi ${ }^{\text {iII }}$ method was $0.2 \mu \mathrm{g} \mathrm{L}{ }^{-1}$; the Asi ${ }^{V}$ LOD was $0.5 \mu \mathrm{g} \mathrm{L}{ }^{-1}$.

\section{Data analysis}

In this study, As concentrations adjusted for urine creatinine were used for all statistical analyses. Creatinine levels were determined by a chemoluminescence immunoassay. The normal distribution of the data was verified by the Shapiro-Wilk test. Because of the low detectable frequency for Asi ${ }^{\mathrm{V}}$, total inorganic As (Asi, the sum of Asi ${ }^{\mathrm{III}}$ and $\mathrm{Asi}{ }^{\mathrm{V}}$ ) was used in the data analysis. The percentage of each As species (\%DMA, \%MMA, and \%Asi) was calculated by dividing their corresponding concentration by the total As metabolites in urine (the sum of DMA, MMA, and Asi). The As methylation indices are defined as the primary As methylation index (PMI; MMA/Asi) and the secondary As methylation index (SMI; DMA/MMA) [33,34]. The averaged measurements of the two urine samples from each participant were previously reported [35], except for the data shown in Figure 1. Continuous variables between two groups (e.g., drinking versus non-drinking, smoking versus non-smoking) were compared using the Student's $t$ test. Non-normally distributed variables were analyzed using the nonparametric Mann-Whitney $U$-test. As species concentrations were logarithmically transformed to increase symmetry and normal distribution [36]. The effects of adjusted As species and methylation indices on semen quality with regard to age, smoking/drinking status and abstinence duration were studied using binary logistic regressions, where the continuous variables were dichotomized with cut-offs of the median. For each of the three sperm quality parameters, the data above the reference were used as the controls, without regard to the other two parameters. The statistical package of SPSS 18.0 for Windows was used for all statistical analyses.

\section{Results}

\section{Demographics and semen diagnosis}

The participants' demographic characteristics and semen parameters are listed in Table 1. All study participants answered the structured questionnaire and completed the semen quality test. Participant ages ranged from 23 to 43 years, with an average age of 32 years. Although it has been suggested that creatinine concentration $(0.62$ $\pm 0.53 \mathrm{~g} \mathrm{~L}^{-1}$ ) correlates with As exposure [37], our findings do not support this assertion. Heavy smokers and drinkers had higher BMIs than other participants. Thirty-two men (33.3\%) had normal (above-reference values) semen parameters. 


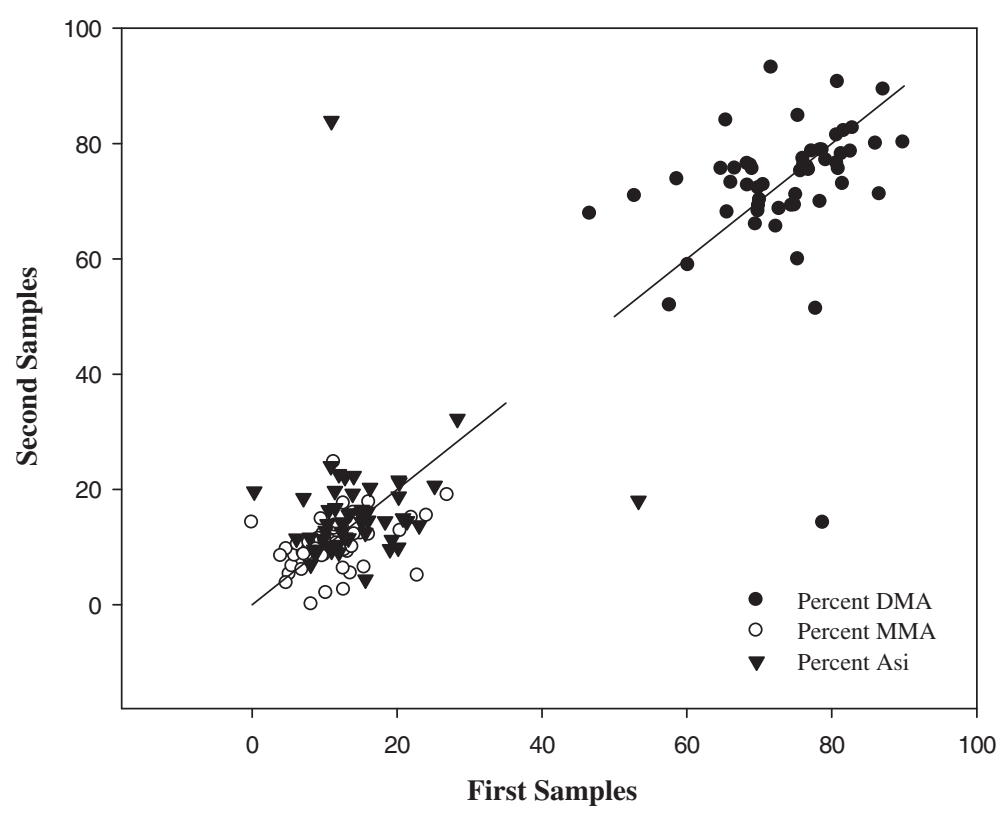

Figure 1 Correlations of \%DMA, \%MMA and \%Asi (per cent DMA, per cent MMA and per cent Asi, respectively) between the repeat samples from study participants.

\section{Arsenic (As) species concentrations and profile}

Table 2 shows the geometric mean concentrations and proportions of As species stratified by groups based on smoking and drinking. Because of the narrow age range, data were not age-adjusted when comparing the differences between the variables. The results of the Student's $t$-test and the Mann-Whitney $U$-test, which are expressed in $P$ values, are listed below the corresponding variables. The geometric mean concentrations (expressed as $\mu \mathrm{g} \mathrm{g}^{-1}$ creatinine) of urinary AsB, DMA, MMA and Asi for all participants were $7.49,20.9,2.77$, and $4.03 \mu \mathrm{g} \mathrm{g}^{-1}$, respectively, while the mean concentrations ( \pm SD, standard deviation) were $14.0( \pm 24.8), 26.2( \pm 13.7), 3.66( \pm 3.33)$ and 4.89 $( \pm 3.67) \mu \mathrm{g} \mathrm{g} \mathrm{g}^{-1}$, respectively. The geometric mean percentages of DMA, MMA and Asi for all study participants, calculated from non-creatinine adjusted urinary arsenic concentrations were $75.4 \%, 10.3 \%$ and $14.3 \%$, and they were very similar to creatinine-adjusted As concentration values presented in Table 2. There were no significant differences in AsB levels between all pairs of demographic variables. The differences in MMA and \%MMA between smokers and non-smokers were significant. Consumption of alcohol had no detectable impact on As species concentrations and profiles in the urine.

The Spearman and log-scale Pearson correlation coefficients between the two As species are listed in Table 3. The maximum correlation coefficient $(\mathrm{R})$ between MMA and Asi was 0.82. There were strong correlations in DMA, MMA and Asi. The correlation coefficients for AsB, DMA, MMA and Asi were significant $(P<0.01)$.
The statistical analysis of the two samples contributed per study participant showed that the As species concentrations did not exhibit a significant correlation, except AsB $(\mathrm{R}=0.59, P<0.01)$. When comparing the percentages of the species between the two samples, a stronger correlation for \%DMA ( $\mathrm{R}=0.47, P<0.01)$, \%MMA $(\mathrm{R}=0.45, P<0.01$ ) and \%Asi $(\mathrm{R}=0.23, P=0.09)$ was observed when compared with the previously-mentioned species concentrations (Figure 1).

\section{Methylation index profile}

The primary As methylation index (PMI) and the secondary As methylation index (SMI) were mutually compared between the different groups based on demographic variables. Although have there was a significant difference for MMA and \%MMA between smoker and the non-smoker categories (Table 2), the difference for PMI was not significant. However, a significant difference for SMI between smokers versus non-smokers $(P=0.05)$ was observed.

\section{Arsenic (As) species versus semen parameters}

Adjusted odds ratios (ORs) for the relationships between dichotomized semen parameters and creatinine-adjusted As species are presented in Table 4. We observed that DMA concentrations above the median were significantly associated with below-reference sperm concentration (ORs: 1.0 - 7.2; $P=0.02$, corrected for age, BMI, abstinence, smoking and drinking) as well as DMA\% and sperm concentration (ORs: $1.0-7.0 ; P=0.02$ ). 
Table 1 Subject demographics and distribution of semen parameters (Mean \pm SD)

\begin{tabular}{|c|c|c|}
\hline & Number (\%) & Mean \pm SD \\
\hline All & $96(100)$ & \\
\hline Age (years) & & $32 \pm 4.8$ \\
\hline BMI $\left(\mathrm{kg} \mathrm{m}^{-2}\right)$ & & $23.5 \pm 3.27$ \\
\hline Creatinine $\left(\mathrm{g} \mathrm{L}^{-1}\right)$ & & $0.98 \pm 0.60$ \\
\hline \multicolumn{3}{|l|}{ Smoking status } \\
\hline Smoker & $38(40)$ & \\
\hline Non-smoker & $58(60)$ & \\
\hline \multicolumn{3}{|l|}{ Alcohol drinking status } \\
\hline Drinker & $57(59)$ & \\
\hline Non-drinker & $39(41)$ & \\
\hline \multicolumn{3}{|l|}{ Education status } \\
\hline >high school & $54(56)$ & \\
\hline shigh school & $42(44)$ & \\
\hline \multicolumn{3}{|l|}{ Semen parameters ${ }^{a}$} \\
\hline Sperm concentration (million $\mathrm{mL}^{-1}$ ) & & $72.3 \pm 48.6$ \\
\hline Subjects $<20$ million $\mathrm{mL}^{-1}$ & $13(14)$ & \\
\hline Sperm motility & & $63.6 \% \pm 19.4 \%$ \\
\hline Subjects $<50 \%$ motile sperm & $24(25)$ & \\
\hline Semen volume $(\mathrm{mL})$ & & $2.74 \pm 0.88$ \\
\hline Subjects $<2 \mathrm{~mL}$ & $13(14)$ & \\
\hline Normal sperm morphology rate & & $16.6 \% \pm 8.8 \%$ \\
\hline Subjects $<15 \%$ & $45(47)$ & \\
\hline \multicolumn{3}{|l|}{ Abstinence time } \\
\hline 2 days & $9(9)$ & \\
\hline 3 days & $22(23)$ & \\
\hline 4 days & $15(16)$ & \\
\hline 5 days & $24(25)$ & \\
\hline$\geq 6$ days & $26(27)$ & \\
\hline
\end{tabular}

${ }^{a}$ WHO guidelines for sperm concentration, motility, volume and sperm morphology are sperm concentration $\geq 20 \times 10^{6} / \mathrm{mL}$, motility $\geq 50 \%$ motile, semen volume $\geq 2 \mathrm{~mL}$, and Normal sperm morphology rate $\geq 15 \%$.

${ }^{\mathrm{b}}$ sperm concentration, sperm motility and normal sperm morphology rate are non-normally distributed. The medians are $66.6,68.8 \%$ and $15.2 \%$, and the $95 \%$ percentiles are $62.5 \sim 82.2,59.7 \% \sim 67.5 \%$ and $14.7 \sim 18.4 \%$, respectively.

\section{Discussion and Conclusions}

Urinary As species have been used as indicators of human exposure to As [38]. Analyzing the urinary profile of AsB, DMA, MMA, Asi ${ }^{\text {III }}$ and Asi ${ }^{\mathrm{V}}$ could yield information on the exposure sources and dietary origin of these inorganic and organic species $[31,39]$. The profile could also lend important insights into understanding As metabolism and its effects on human health [40]. The urinary species profile of \%DMA, \%MMA and \%Asi are observed to be fairly stable over time and are useful in understanding the relationship between As exposure and health consequences [41]. Some researchers have identified associations between As'
Table 2 Differences in As species (geometric means \pm SD) by demographic variables ${ }^{\text {a }}$

\begin{tabular}{llllllll}
\hline & \multicolumn{7}{l}{ Urinary concentration $\left(\boldsymbol{\mu \mathbf { g ~ g ~ } ^ { - 1 }}\right.$ creatinine $)$} \\
\cline { 2 - 8 } Variable & AsB & DMA & MMA & Asi & \%DMA & \%MMA & \%Asi \\
\hline All & 7.49 & 20.9 & 2.77 & 4.03 & 73.4 & 9.73 & 14.2 \\
& \pm 24.8 & \pm 13.7 & \pm 3.33 & \pm 3.67 & \pm 8.44 & \pm 4.65 & \pm 6.88 \\
25th & 3.41 & 14.8 & 1.76 & 2.82 & 70.3 & 7.51 & 11.8 \\
50th & 6.63 & 20.7 & 2.59 & 3.81 & 75.4 & 10.1 & 14.2 \\
75th & 13.0 & 30.9 & 4.19 & 5.79 & 78.9 & 12.9 & 16.6 \\
Smoker & 6.91 & 18.7 & 2.22 & 3.61 & 73.6 & 8.72 & 14.2 \\
& \pm 25.9 & \pm 11.9 & \pm 3.45 & \pm 3.75 & \pm 9.88 & \pm 4.37 & \pm 8.17 \\
Non- & 7.94 & 22.6 & 3.24 & 4.36 & 73.3 & 10.5 & 14.2 \\
smoker & \pm 27.7 & \pm 14.8 & \pm 3.22 & \pm 3.63 & \pm 7.33 & \pm 4.04 & \pm 5.86 \\
P-value & 0.60 & 0.12 & $0.01 * * \mathrm{~b}$ & 0.16 & 0.29 & $0.04 *$ & 0.94 \\
Drinker & 7.28 & 21.3 & 2.78 & 3.89 & 74.2 & 9.67 & 13.5 \\
& \pm 19.7 & \pm 12.7 & \pm 3.47 & \pm 3.66 & \pm 7.90 & \pm 4.99 & \pm 5.73 \\
Non- & 7.82 & 20.3 & 2.76 & 4.25 & 72.3 & 9.82 & 15.1 \\
drinker & \pm 34.8 & \pm 15.3 & \pm 3.15 & \pm 3.74 & \pm 9.19 & \pm 4.17 & \pm 8.21 \\
P-value & 0.85 & 0.67 & 0.96 & 0.51 & 0.55 & 0.83 & 0.34
\end{tabular}

${ }^{a}$ The statistical difference was listed with $P$-value.

Proportion of each As species (\%DMA, \%MMA, and \%Asi) were calculated by dividing their concentration by the total As metabolites in urine (the sum of DMA, MMA and Asi).

${ }^{\mathrm{b}}$ The comparison which the $P$-value applies are smoking habit and dinking habit, respectively, ${ }^{* *}$ Difference is significant at the 0.01 level; *Difference is significant at the 0.05 level.

methylating capacity (urinary \%MMA) and related cancer risks $[3,42,43]$.

Source analysis of exposure to arsenic (As)

Urinary $\mathrm{Asi} i^{\mathrm{III}}$ is usually associated with the consumption of mineral water, and urinary AsB is usually associated with the consumption of seafood. In this study, Asi $i^{\mathrm{III}}$ and $A s i{ }^{V}$ concentrations were lower than the published data for populations exposed to As in Asi-contaminated drinking water [44]. The average concentration of total As in drinking water was $0.023 \mathrm{mg} \mathrm{L}^{-1}$ in Chongqing [45]. Because our participants were not exposed to an Aspolluted geological environment, dietary intake could be the main source of exposure. The urinary concentrations of AsB and DMA (geometric mean AsB 7.49 and median DMA $20.9 \mu \mathrm{g} \mathrm{L}^{-1}$ ) in our cohort were lower than that

Table 3 Spearman and log-scale Pearson correlations between different arsenic species

\begin{tabular}{|c|c|c|c|c|c|c|c|c|}
\hline & \multicolumn{4}{|c|}{ Spearman } & \multicolumn{4}{|c|}{ Pearson (log-scale) } \\
\hline & AsB & DMA & MMA & Asi & AsB & DMA & MMA & Asi \\
\hline AsB & 1 & $0.47^{* *}$ & $0.54^{* *}$ & $0.48^{* *}$ & 1 & $0.52^{* *}$ & $0.46^{* *}$ & $0.49^{* *}$ \\
\hline DMA & & 1 & $0.74^{* *}$ & $0.70^{* *}$ & & 1 & $0.76^{* *}$ & $0.73^{* *}$ \\
\hline MMA & & & 1 & $0.76^{* *}$ & & & 1 & $0.82^{* *}$ \\
\hline Asi & & & & 1 & & & & 1 \\
\hline
\end{tabular}

** means that at the 0.01 confidence level (two sides), the correlations is significant. 
Table 4 Association of the below-reference values ${ }^{a}$ of sperm concentration, sperm motility and semen volume with dichotomised of As levels $(n=96)^{b}$

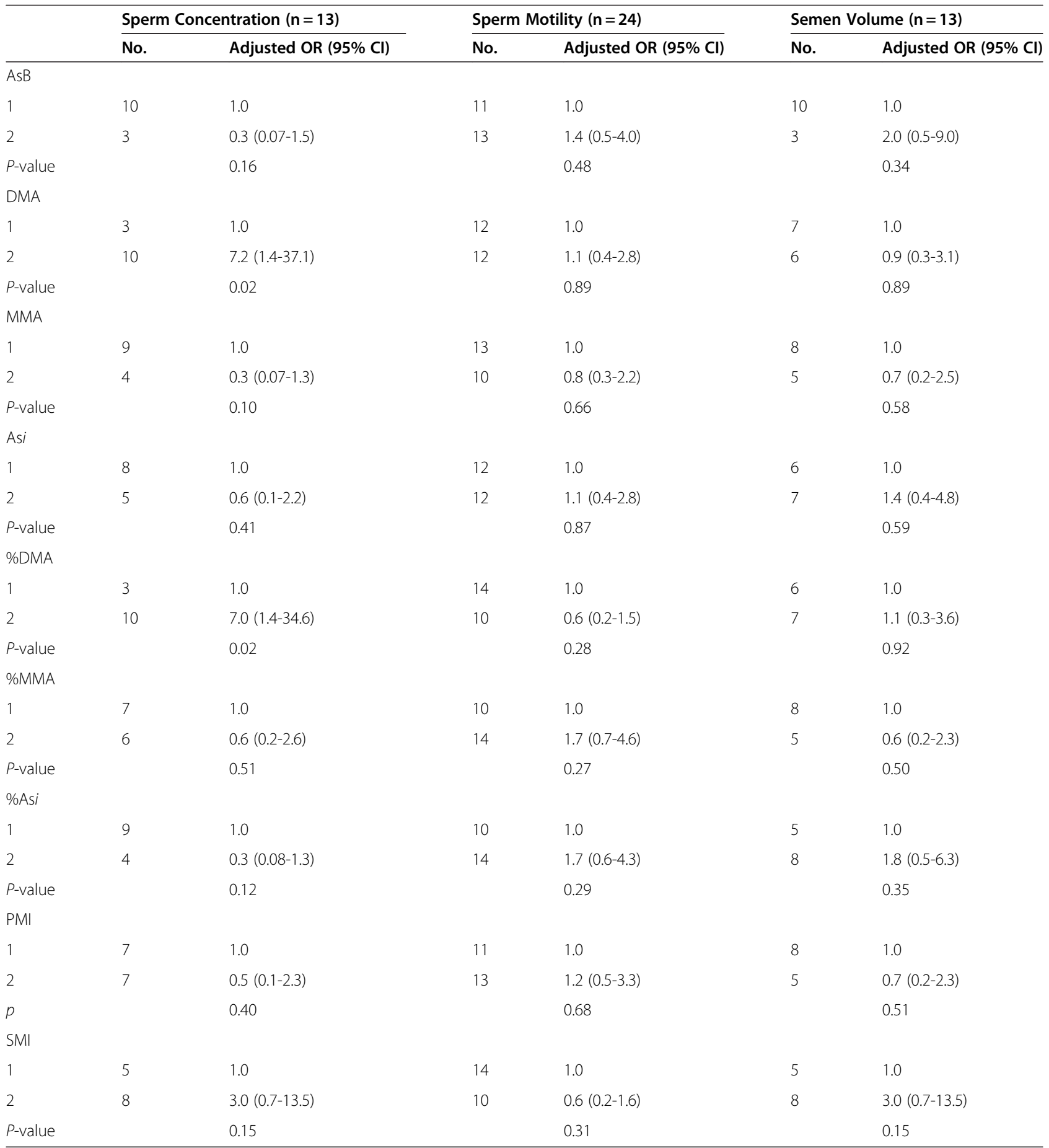

${ }^{a}$ Comparison group is at or above reference value for sperm concentration $\left(\geq 20 \times 10^{6} / \mathrm{mL}\right)$, motility $(\geq 50 \%$ motile), and semen volume $(\geq 2 \mathrm{~mL})$.

${ }^{\mathrm{b}}$ Adjusted for age (continuous), BMI (continuous), abstinence time (5 categories: $2,3,4,5$, and $\geq 6$ days), smoking habit (non-smoker and smoker), drinking habit (non-drinker and drinker).

reported for individuals who had a preference for seafood intake (median AsB 61.3 and 74.5, median DMA 41.1 and $42.6 \mu \mathrm{g} \mathrm{L}^{-1}$, respectively) [32,46]. The mutually significant correlation of all urinary As species (Table 3) suggests a common source of exposure [39], and the significant correlations of AsB and Asi ${ }^{\mathrm{III}}$ between the two contributed samples support a reasonably stable route of exposure. Previous studies have shown that rice can effectively concentrate As from soil [47]; the total As concentrations observed in polished (white) rice from Sichuan province 
(Chongqing previously belonged to Sichuan province) ranged from 0.043 to $0.208 \mu \mathrm{g} \mathrm{g}^{-1}$, and the inorganic As concentration ranged from 0.034 to $0.167 \mu \mathrm{g} \mathrm{g}^{-1}$ [48]. With a rice consumption of $0.5 \mathrm{~kg} \mathrm{day}^{-1}$ and a water consumption of $2 \mathrm{Lday}^{-1}$ for adults with an average body weight of $65 \mathrm{~kg}$, the daily intake of inorganic As was about 0.26-1.28 $\mu \mathrm{g} \mathrm{kg}{ }^{-1}$. This dose exceeded the daily oral As reference dose of $0.3 \mu \mathrm{g} \mathrm{kg}^{-1}$ [49]. Because rice is the staple food for our participants, it is possible that their primary inorganic As source derives from this exposure route. For AsB, the subjects may be exposed to AsB from dry brown algae and agar-agar because fresh seafood is typically unavailable for inland inhabitants. However, the human body does not metabolize it, but rather excretes it from urine directly $[50,51]$.

\section{Species metabolism and methylation indices}

The correlations among Asi, MMA and DMA are stronger than the correlations between AsB and Asi, MMA and DMA (Table 3), which suggests that the study participants metabolized Asi into MMA and DMA. Between smokers and non-smokers, there are significant differences in MMA concentrations and \%MMA, as smokers exhibit lower MMA concentrations. This difference disappeared when the difference of MMA is adjusted by Asi (i.e., PMI), but when it is adjusted by DMA (i.e., SMI) the difference is still significant as smokers have a higher SMI. This observation supports the notion that smoking may increase levels of As metabolites [31,52]. However, we didn't observe an association between Asi and smoking $[53,54]$, which may suggest that the urinary As concentration was a consequence of arsenical pesticide used on tobacco. Drinking shows no effect on the As species' concentrations and profiles in the participants. This result is in accordance with previous studies [42]. These findings suggest that As exposure from alcohol may be negligible.

\section{Arsenic (As) species associated to semen parameters}

It has been suggested that As may exert an influence on the endocrine system. Arsenite can inhibit the growth of MCF-7 cells by reducing the growth stimulatory effects of oestrogen [15]. Sodium arsenite treatment also decreases circulating levels of oestradiol in rats [16]. Furthermore, the steroidogenic dysfunction after As exposure has been reported to result in infertility in male rats [21-24]. This may suggest a similar effect in humans. However, few population studies have been reported examining this possibility [25].

Among the investigated associations between the information on As burden [species (AsB, DMA, MMA, Asi), species percentages (\%DMA, \%MMA, \%Asi) and methylation indices (PMI and SMI)] and semen parameters (sperm concentration, sperm motility and semen volume), the dosage correlations between DMA or \% DMA versus sperm concentrations are similarly significant. The higher DMA concentrations may correlate with lower sperm concentrations. An in vitro experiment indicated that organic arsenicals exhibited rapid sperm immobilizing activity [55]. The As-treated animals exhibited decreased sperm counts, sperm motility and testicular weight when compared with untreated animals [56]. As disrupts the process of meiosis and post-meiotic stages of spermatogenesis, and acute exposure causes rapid and extensive disruption of spermatogenesis in mice [24]. Our results suggest that exposure to environmental levels of arsenic may also result in low sperm concentrations in humans. However, there are no associations between DMA concentrations and sperm motility or semen volume. As one of the main As species, DMA is the metabolic product of As in humans. It is unclear whether it is DMA itself or the process of As metabolism that affects sperm production. Recently, rodent model experiments have indicated that As impairs male reproductive functions by inducing oxidative stress [57], but the mechanism in human has not yet been verified.

For the first time reported, we demonstrate that increasing exposure to the As species DMA inversely correlates with sperm levels in humans. The study participants were recruited from hospital patients and not from the general population, which may introduce bias; however, these are otherwise healthy individuals. The correlations of As concentrations between the first and second contributed urine samples were significant although weakly so, which was unexpected. That may be attributed to different times of day for sample collection, an occasional higher exposure dose from something such as seafood, or the relatively small sample size. The result may also be inflated by the multiple comparisons. However, moderate associations between As exposure and semen quality may have been overlooked because of the small sample size. Due to the ubiquitous exposure to As, we recommend that these initial results should be confirmed in the larger population study.

\section{Conclusions}

As is a well-known carcinogen that has been recognized as an endocrine disrupter at environmental levels. In China and throughout Asia, huge populations depend on rice as a staple food, which can concentrate higher levels of inorganic As in the grain than wheat. Rice may be the main source of As intake in these subjects. For the first time, we found that the general As exposure may be associated with reduced human semen quality. By linking these cases, we can see that the general population may be exposed to inorganic As via rice, and its endocrine disrupting effects may further decrease semen 
quality. Because of the spread of As in the environment, further research is urgently needed to fully understand its health effects on the semen quality.

\section{Abbreviations}

AsB: Arsenobetaine; DMA: $\left(\mathrm{CH}_{3}\right)_{2} \mathrm{AsOOH}$; $\mathrm{MMA}:\left(\mathrm{CH}_{3}\right) \mathrm{AsO}(\mathrm{OH})_{2}$; Asi: Inorganic arsenic; PMI: The primary arsenic methylation index (MMA/Asi); SMI: The secondary arsenic methylation index (DMA/MMA); ORs: Odds ratios.

\section{Competing interests}

The authors declare that they have no competing interest.

\section{Acknowledgements}

We thank doctoral candidate Gang Li for supplying us with the data of total As and inorganic As in rice of Sichuan. We also thank Prof. Francis $L$ Martin from Centre for Biophotonics, LEC, Lancaster University for helping the English improvement. This work was financially supported by Chinese Academy of Sciences (CAS) Hundred Talent Program 2010 for Human Exposure to Environmental Pollutant and Health Effect, NSFC 2011 research foundation (21177123), the MOST for Combined Pollution and Ecosystem Health in Urban Agglomeration (2009DFB90120) and the CAS/SAFEA International Partnership Program for Creative Research Teams (KZCX2-YW-T08).

\section{Author details}

'Key Lab of Urban Environment and Health, Institute of Urban Environment, Chinese Academy of Sciences, 1799 Jimei Road, Xiamen 361021, China. ${ }^{2}$ Chongqing Key Laboratory of Birth Defects and Reproductive Health, The Affiliated Hospital of Chongqing Institute for Population and Family Planning, Chongqing 400020, China. ${ }^{3}$ Environmental Health Laboratory Branch, California Department of Public Health, Richmond, CA 94804, USA.

\section{Authors' contributions}

WX and FL carried out the As determination, performed the statistical analysis and drafted the manuscript. HB, MC, LL and CL participated in the subject recruitment, urine sample collection, questionnaire and semen analysis. LL carried out the determination of urine creatinine and performed the statistical analysis. HS conceived the study, and participated in the design and coordination of the study, and helped to draft the manuscript. YGZ participated in the study design. JS and SD helped to draft the manuscript. All authors read and approved the final manuscript

Received: 21 February 2012 Accepted: 9 July 2012

Published: 9 July 2012

\section{References}

1. Abernathy CO, Thomas DJ, Calderon RL: Health effects and risk assessment of arsenic. J Nutr 2003, 133:1536S-1538S.

2. Villa-Bellosta R, Sorribas V: Role of rat sodium/phosphate cotransporters in the cell membrane trasport of arsenate. Tocicol Appl Pharmacol 2008, 232:125-134.

3. Steinmaus C, Yuan Y, Kalman D, Rey OA, Skibola CF, Dauphine D, et al: Individual differences in arsenic metabolism and lung cancer in a casecontrol study in Cordoba, Argentina. Toxicol Appl Pharmacol 2010, 247:138-145.

4. Valenzuela OL, Borja-Aburto VH, Garcia-Vargas GG, Cruz-Gonzalez MB, Garcia-Montalvo EA, Calderon-Aranda ES, et al: Urinary trivalent methylated arsenic species in a population chronically exposed to inorganic arsenic. Environ Health Perspect 2005, 113:250-254.

5. Van Herreweghe S, Swennen R, Vandecasteele C, Cappuyns V: Solid phase speciation of arsenic by sequential extraction in standard reference materials and industrially contaminated soil samples. Enviton Pollut 2003, 122:323-342.

6. Abernathy CO, Liu YP, Longfellow D, Aposhian HV, Beck B, Fowler B, et al: Arsenic: health effects, mechanisms of actions, and research issues. Environ Health Perspect 1999, 107:593-597.

7. Aposhian HV, Aposhian MM: Arsenic toxicology: five questions. Chem Res Toxicol 2006, 19:1-15.

8. Kitchin KT: Recent advances in arsenic carcinogenesis: modes of action, animal model systems, and methylated arsenic metabolites. Toxicol Appl Pharmacol 2001, 172:249-261.
9. Rossman TG: Mechanism of arsenic carcinogenesis: an integrated approach. Mutat Res 2003, 533:37-65.

10. Bodwell JE, Gosse JA, Nomikos AP, Hamilton JW: Arsenic disruption of steroid receptor gene activation: Complex dose-response effects are shared by several steroid receptors. Chem Res Toxicol 2006, 19:1619-1629.

11. Bodwell JE, Kingsley LA, Hamilton JW: Arsenic at very low concentrations alters glucocorticoid receptor (GR)-mediated gene activation but not GRmediated gene repression: Complex dose-response effects are closely correlated with levels of activated GR and require a functional GR DNA binding domain. Chem Res Toxicol 2004, 17:1064-1076.

12. Davey JC, Bodwell JE, Gosse JA, Hamilton JW: Arsenic as an endocrine disruptor: Effects of arsenic on estrogen receptor-mediated gene expression in vivo and in cell culture. Toxicol Sci 2007, 98:75-86.

13. Davey JC, Nomikos AP, Wungjiranirun M, Sherman JR, Ingram L, Batki C, et al: Arsenic as an endocrine disruptor: Arsenic disrupts retinoic acid receptor- and thyroid hormone receptor-mediated gene regulation and thyroid hormone-mediated amphibian tail metamorphosis. Environ Health Perspect 2008, 116:165-172.

14. Kaltreider RC, Davis AM, Lariviere JP, Hamilton JW: Arsenic alters the function of the glucocorticoid receptor as a transcription factor. Environ Health Perspect 2001, 109:245-251.

15. Chow SK, Chan JY, Fung KP: Suppression of cell proliferation and regulation of estrogen receptor alpha signaling pathway by arsenic trioxide on human breast cancer MCF-7 cells. J Endocrinol 2004, 182:325-337.

16. Chatterjee A, Chatterji U: Arsenic abrogates the estrogen-signaling pathway in the rat uterus. Reprod Biol Endocrinol 2010, 8:11.

17. Stoica A, Pentecost E, Martin MB: Effects of arsenite on estrogen receptoralpha expression and activity in MCF-7 breast cancer cells. Endocrinology 2000, 141:3595-3602.

18. Watson WH, Yager JD: Arsenic: extension of its endocrine disruption potential to interference with estrogen receptor-mediated signaling. Toxicol Sci 2007, 98:1-4.

19. Golub MS, Macintosh MS, Baumrind N: Developmental and reproductive toxicity of inorganic arsenic: animal studies and human concerns. $J$ Toxicol Environ Health B Crit Rev 1998, 1:199-237.

20. Shukla JP, Pandey K: Impaired spermatogenesis in arsenic treated freshwater fish, Colisa fasciatus (Bl. and Sch.). Toxicol Lett 1984, 21:191-195.

21. Biswas R, Poddar S, Mukherjee A: Investigation on the genotoxic effects of long-term administration of sodium arsenite in bone marrow and testicular cells in vivo using the comet assay. J Environ Pathol Toxicol Oncol 2007, 26:29-37.

22. Sarkar M, Chaudhuri GR, Chattopadhyay A, Biswas NM: Effect of sodium arsenite on spermatogenesis, plasma gonadotrophins and testosterone in rats. Asian J Androl 2003, 5:27-31.

23. Jana K, Jana S, Samanta PK: Effects of chronic exposure to sodium arsenite on hypothalamic-pituitary-testicular activities in adult rats: possible an estrogenic mode of action. Reprod Biol Endocrinol 2006, 4:9.

24. Sarkar S, Hazra J, Upadhyay S, Singh R, Chowdhury A: Arsenic induced toxicity on testicular tissue of mice. Indian J Physiol Pharmacol 2008, 52:84-90.

25. Leke RJ, Oduma JA, Bassol-Mayagoitia S, Bacha AM, Grigor KM: Regional and geographical variations in infertility: effects of environmental, cultural, and socioeconomic factors. Environ Health Perspect 1993, 101:73-80.

26. Hsieh Fl, Hwang TS, Hsieh YC, Lo HC, Su CT, Hsu HS, et al: Risk of Erectile Dysfunction Induced by Arsenic Exposure through Well Water Consumption in Taiwan. Environ Health Perspect 2008, 116:532-536

27. Zheng $Y, W u J, N g ~ J C$, Wang G, Lian W: The absorption and excretion of fluoride and arsenic in humans. Toxicol Lett 2002, 133:77-82.

28. WHO: Laboratory manual for the examination of human semen and spermcervical mucus interaction. Cambridge: Cambridge University Press; 1999.

29. Jouannet P, Ducot B, Feneux D, Spira A: Male factors and the likelihood of pregnancy in infertile couples. I. Study of sperm characteristics. Int I Androl 1988, 11:379-394.

30. Kruger T, Acosta A, Simmons K, Swanson R, Matta J, Oehninger S: Predictive value of abnormal sperm morphology in in vitro fertilization. Fertil Steril 1988, 49:112-117.

31. Lindberg AL, Goessler W, Gurzau E, Koppova K, Rudnai P, Kumar R, et al: Arsenic exposure in Hungary, Romania and Slovakia. J Environ Monit 2006, 8:203-208.

32. Hata A, Endo $Y$, Nakajima $Y$, Ikebe M, Ogawa M, Fujitani N, et al: HPLC-ICPMS speciation analysis of arsenic in urine of Japanese subjects without occupational exposure. J Occup Health 2007, 49:217-223. 
33. Parvez F, Chen Y, Brandt-Rauf PW, Bernard A, Dumont X, Slavkovich V, et al: Nonmalignant respiratory effects of chronic arsenic exposure from drinking water among never-smokers in Bangladesh. Environ Health Perspect 2008, 116:190-195.

34. Huang YK, Huang YL, Hsueh YM, Wang JTJ, Yang MH, Chen CJ: Changes in Urinary Arsenic Methylation Profiles in a 15-Year Interval after Cessation of Arsenic Ingestion in Southwest Taiwan. Environ Health Perspect 2009, 117:1860-1866.

35. Steinmaus C, Yuan Y, Kalman D, Atallah R, Smith AH: Intraindividual variability in arsenic methylation in a US population. Cancer Epidemiol Biomarkers Prev 2005, 14:919-924.

36. Pellizzari ED, Clayton CA: Assessing the measurement precision of various arsenic forms and arsenic exposure in the National Human Exposure Assessment Survey (NHEXAS). Environ Health Perspect 2006, 114:220-227.

37. Basu A, Mitra S, Chung J, Mazumder DNG, Ghosh N, et al: Creatinine, Diet, Micronutrients, and Arsenic Methylation in West Bengal. India. Environ Health Perspect 2011, 119:1308-1313.

38. Heitland P, Koster HD: Comparison of different medical cases in urinary arsenic speciation by fast HPLC-ICP-MS. Int J Hyg Environ Health 2009, 212:432-438.

39. Soleo L, Lovreglio P, lavicoli S, Antelmi A, Drago I, Basso A, et al: Significance of urinary arsenic speciation in assessment of seafood ingestion as the main source of organic and inorganic arsenic in a population resident near a coastal area. Chemosphere 2008, 73:291-299.

40. Brima El, Haris PI, Jenkins RO, Polya DA, Gault AG, Harrington CF: Understanding arsenic metabolism through a comparative study of arsenic levels in the urine, hair and fingernails of healthy volunteers from three unexposed ethnic groups in the United Kingdom. Toxicol Appl Pharmacol 2006, 216:122-130.

41. Steinmaus C, Carrigan K, Kalman D, Atallah R, Yuan Y, Smith AH: Dietary intake and arsenic methylation in a U.S. population. Environ Health Perspect 2005, 113:1153-1159.

42. Yu RC, Hsu KH, Chen CJ, Froines JR: Arsenic methylation capacity and skin cancer. Cancer Epidemiol Biomarkers Prev 2000, 9:1259-1262.

43. Pu YS, Yang SM, Huang YK, Chung CJ, Huang SK, Chiu AWH, et al: Urinary arsenic profile affects the risk of urothelial carcinoma even at low arsenic exposure. Toxicol Appl Pharmacol 2007, 218:99-106.

44. Meza MM, Kopplin MJ, Burgess JL, Gandolfi AJ: Arsenic drinking water exposure and urinary excretion among adults in the Yaqui Valley, Sonora, Mexico. Environ Res 2004, 96:119-126.

45. Qian QIAO, Gang-cai CHEN, Ren-wei CHANG: Investigation and Analysis on State of Drinking Water in Rural Areas of Chongqing. Journal of Southwest China Normal University (Natural Science Edition) 2010, 35:175-179.

46. Suzuki Y, Shimoda Y, Endo Y, Hata A, Yamanaka K, Endo G: Rapid and Effective Speciation Analysis of Arsenic Compounds in Human Urine using AnionExchange Columns in HPLC-ICP-MS. J Occup Health 2009, 51:380-385.

47. Chen Z, Zhu YG, Liu WJ, Meharg AA: Direct evidence showing the effect of root surface iron plaque on arsenite and arsenate uptake into rice (Oryza sativa) roots. New Phytol 2005, 165:91-97.

48. Li G, Sun G-X, Williams PN, Nunes L, Zhu Y-G: Inorganic arsenic in Chinese food and its cancer risk. Environ Int 2011, 37:1219-1225.

49. Arsenic: Inorganic (CASRN 7440-38-2), Intergrated Risk Information System. Washington, DC: U.S: Environmental Protection Agency; http://www.epa. gov/iris/subst/0278.htm.

50. Francesconi KA, Tanggaar R, McKenzie CJ, Goessler W: Arsenic metabolites in human urine after ingestion of an arsenosugar. Clin Chem 2002, 48:92-101.

51. Lai WWM, Sun YM, Ting E, Cullen WR, Reimer KJ: Arsenic speciation in human urine: are we all the same? Toxicol Appl Pharmacol 2004, 198:297-306.

52. Tseng CH: Blackfoot disease and arsenic: A never-ending story. J Environ Sci Health C Environ Carcinog Ecotoxicol Rev 2005, 23:55-74.

53. Steinmaus C, Moore LE, Shipp M, Kalman D, Rey OA, Biggs ML, et al: Genetic polymorphisms in MTHFR 677 and 1298, GSTM1 and T1, and metabolism of arsenic. J Toxicol Environ Health A 2007, 70:159-170.

54. Caceres DD, Pino P, Montesinos N, Atalah E, Amigo H, Loomis D: Exposure to inorganic arsenic in drinking water and total urinary arsenic concentration in a Chilean population. Environ Res 2005, 98:151-159.

55. Uckuna Fatih M, X-PL Osmond J, Cruzc D: Human sperm immobilizing activity of aminophenyl arsenic acid and its $\mathrm{N}$-substituted quinazoline, pyrimidine, and purine derivatives: protective effect of glutathione. Reprod Toxicol 2002, 16:57.
56. Omura M, Hirata M, Tanaka A, Zhao M, Makita Y, Inoue N, et al: Testicular toxicity evaluation of arsenic-containing binary compound semiconductors, gallium arsenide and indium arsenide, in hamsters. Toxicol Lett 1996, 89:123-129.

57. Chang SI, Jin B, Youn P, Park C, Park JD, Ryu DY: Arsenic-induced toxicity and the protective role of ascorbic acid in mouse testis. Toxicol Appl Pharmacol 2007, 218:196-203.

doi:10.1186/1476-069X-11-46

Cite this article as: Xu et al.: Environmental exposure to arsenic may reduce human semen quality: associations derived from a Chinese cross-sectional study. Environmental Health 2012 11:46.

\section{Submit your next manuscript to BioMed Central and take full advantage of:}

- Convenient online submission

- Thorough peer review

- No space constraints or color figure charges

- Immediate publication on acceptance

- Inclusion in PubMed, CAS, Scopus and Google Scholar

- Research which is freely available for redistribution 